\title{
Success brings new challenges in circumcision campaign
}

Remarkable progress has been made during the 13 years since the publication of three African clinical trials showing a $60 \%$ reduction in HIV transmission following adult male circumcision. As a result of a range of public health and clinical interventions, among which male circumcision is the most enduring and cost-effective, new HIV infections in South Africa (SA) have fallen by $32 \%$ since 2010 and AIDS-related deaths have decreased by $58 \%$ from a peak of 260000 in 2007 to 110000 in 2017. ${ }^{[1]}$

Scale-up of voluntary adult male circumcision began in earnest in 2010, and by the end of 2017, 3.4 million male circumcisions had been performed in SA. ${ }^{[2]}$

In the 14 countries designated high priority (because of high HIV rates and low circumcision prevalence), the World Health Organization (WHO) estimates that the 18.6 million circumcisions already performed have prevented an estimated 230000 new HIV infections, with the number prevented projected to increase to 1.1 million by $2030 .^{[2]}$

The near future appears positive in terms of funding SA's circumcision programme. The budget of the primary external funder, the President's Emergency Plan for AIDS Relief (PEPFAR), is expected to remain stable for the coming fiscal year. PEPFAR is planning to redirect its resources, with SA well placed with a proposed increase of $11 \%$ in funding, while Mozambique is inexplicably budgeted for a disastrous drop of $43 \% \cdot{ }^{[3]}$

There have been bumps in the road, and new challenges are arising. First, the WHO has expended great efforts in promoting two plastic ring devices that were to have simplified the surgical procedure; both have fared poorly in SA. Initial enthusiasm led to $9 \%$ of circumcisions being performed by device (primarily the PrePex) in 2015, which has diminished to nil at present. ${ }^{[4]}$ The need for a prior course of tetanus immunisation, increased pain, malodour, the inconvenience of wearing a plastic ring on the penis for a week, delayed healing, and the additional resources needed for the removal procedure have all reduced enthusiasm for the PrePex and Shang Ring.

SA has not addressed the mismatch between the target population and who is actually getting circumcised. ${ }^{[5]}$ Promotion efforts are being directed towards men, while nearly half of circumcisions are currently being performed on boys 10 - 14 years of age. ${ }^{[4]}$
Payment mechanisms need to be developed to remove barriers to voluntary circumcision. In the private sector, incentives need to be developed to encourage voluntary circumcision in all age groups. In the public sector, contracts are outsourced to three non-governmental organisations via closed tender. ${ }^{[6]}$ Public sector payment directly to medical practitioners would integrate patients better into primary care, increasing participation among doctors and enhancing linkage to care.

Finally, we need simpler circumcision techniques. Open surgical circumcision is time-consuming, requires significant training, and results in suboptimal cosmesis. The Unicirc, developed in SA and Conformité Européenne certified, is fundamentally different from the plastic ring devices. It is a surgical instrument that allows for rapid circumcision without painful injections or sutures. The Unicirc procedure is completed on the day of circumcision, obviating the need for subsequent removal. ${ }^{[7]}$ Its use could facilitate greater throughput and increased satisfaction among SA men.

\section{Peter S Millard \\ University of New England, Portland, Maine, USA}

\section{Norman Goldstuck}

Department of Obstetrics and Gynaecology, Faculty of Medicine and Health Sciences, Stellenbosch University and Tygerberg Hospital,

Cape Town, South Africa

nahumzh@gmail.com

1. Joint United Nations Programme on HIV/AIDS (UNAIDS). Aidsinfo. 2018. http://aidsinfo.unaids. org/ (accessed 1 November 2018)

2. World Health Organization (WHO). Progress Brief: Voluntary medical male circumcision for HIV prevention, July 2018. 2018. https://www.malecircumcision.org/resource/who-progress-briefvoluntary-medical-male-circumcision-hiv-prevention-july-2018 (accessed 1 November 2018), 3. Reliefweb. https://reliefweb.int/sites/reliefweb.int/files/resources/cpio8-jfvkd.pdf (accessed 1 November 2018).

United States President's Emergency Plan for AIDS Relief (PEPFAR). Program results achieved through PEPFAR support: South Africa. 2018. https://data.pepfar.gov/dataSources (accessed 1 November 2018). 5. Millard PS, Goldstuck N. Missed opportunities for circumcising boys. S Afr Med J 2017;107(1):19. https://doi.org/10.7196/SAMJ.2016.v107.i1.12177

6uestion NW2355 to the Minister of Health. 8 October 2018. https://pmg.org.za/committeequestion/10106/ (accessed 1 November 2018).

Alawamlh O, Kim S, Li P, Lee R. Novel devices for adolescent and adult male circumcision. Eur Urol Focus 2018;4(3):329-332. https://doi.org/10.1016/j.euf.2018.06.015

S Afr Med J 2019;109(2):68. DOI:10.7196/SAMJ.2019.v109i2.13821 